BEHAVIOUR

\title{
Relation of sexual risks and prevention practices with individuals' stigmatising beliefs towards HIV infected individuals: an exploratory study
}

\author{
H Liu, X Li, B Stanton, X Fang, R Mao, X Chen, H Yang
}

Sex Transm Infect 2005;81:51 1-516. doi: 10.1136/sti.2005.014977

See end of article for authors' affiliations

.....................

Correspondence to: Hongiie Liu, PhD,

Prevention Research Center, School of

Medicine, Wayne State

University, $4201 \mathrm{St}$

Antoine, UHC-6D, Detroit,

MI 48201-2196, USA;

hongiie@med.wayne.edu

Accepted for publication 29 March 2005

\begin{abstract}
Objective: To investigate how an individual's stigmatising beliefs towards people living with HIV are related to his or her own sexual risk and protective behaviours.

Methods: A cross sectional survey was conducted to assess HIV related stigmatising beliefs, risk sexual behaviours, and preventive practices among sexually experienced rural to urban migrants aged 1830 years in 2002 in Beiijing and Naniing, two large Chinese cities.

Results: Among 2153 migrants, 7.2\% reported having had more than one sexual partner in the previous month, 9.9\% had commercial sex partners, and $12.5 \%$ had an episode of a sexually transmitted disease (STD). Only $18 \%$ reported frequently or always using condoms, with $20 \%$ sometimes or occasionally using them. $57 \%$ of the Chinese migrants were willing to take a voluntary HIV test, and $65 \%$ had HIV related stigmatising beliefs towards people living with HIV. Multiple logistic regression analysis depicts that individual's stigmatising beliefs towards people with HIV were positively associated with having had an episode of an STD, having multiple sex partners, or having had commercial sex partners, and were negatively associated with condom use and the willingness to accept an HIV test.

Conclusion: The finding that one's own stigmatising belief is a potential barrier to HIV related preventive practices highlights the difficulties and challenges in implementing behavioural interventions.
\end{abstract}

in the United States and the collaborating institutes in China (for example, Beijing Normal University and Nanjing University). The study sites and population have been described previously. ${ }^{3}$ Briefly, the study was conducted in 2002 among young migrants (18-30 years of age) in Beijing, China's capital and Nanjing, the capital city of Jiangsu Province in eastern China. The sample was recruited using "quota sampling" of 10 occupational groups. After providing informed consent, participants were asked to complete an anonymous self administered questionnaire in a separate room at their workplace or another location convenient to the participants. The interviewers provided assistance to a few migrants with limited literacy by reading part of the questionnaire. Demographic characteristics of the migrants are described in table 1. A total of 4301 migrants in the two cities were approached. Twenty four $(0.6 \%)$ declined to participate, 69 were deleted from the data file because of either substantial missing data or missing values on key demographic variables. A final sample of 4208 was retained in the study. The participants in the current report were a subsample of 2153 sexually experienced respondents, consisting of $33.8 \%$ females and $46 \%$ of whom were recruited from Beijing. Mean age of the sample was 25 years in Beijing and 26 years in Nanjing. The majority of the participants were ethnic Han $(97 \%)$ and had finished a minimum of middle school education (92.6\%). About half of the respondents (55.6\%) had never been married. They had been migrating to cities for a median of 5 years, with $71 \%$ having been in at least two different cities during their migration. An average monthly income was \$97 (median).

\section{Measures}

Stigmatising beliefs towards people with HIV

Four items were developed to capture the pattern of prejudice, discounting, and discrimination against people

Abbreviations: STD, sexually transmitted diseases

\section{Study sites and participants}

This research study was approved by the institutional review boards at West Virginia University and Wayne State University 
Table 1 Social economic demographics of migrants by migratory cities

\begin{tabular}{|c|c|c|c|c|c|}
\hline & \multicolumn{2}{|c|}{ Beijing } & \multicolumn{2}{|c|}{ Nanjing } & \multirow[b]{2}{*}{ p Value } \\
\hline & No & $\%$ & No & $\%$ & \\
\hline Sex & & & & & 0.29 \\
\hline Male & 645 & 65.0 & 780 & 67.2 & \\
\hline Female & 347 & 35.0 & 381 & 32.8 & \\
\hline Age (years) & \multirow{2}{*}{\multicolumn{2}{|c|}{$25.0(3.5)$}} & \multirow{2}{*}{\multicolumn{2}{|c|}{$26.1(3.6)$}} & $<0.01$ \\
\hline Mean (SD) & & & & & \\
\hline Education & & & & & 0.05 \\
\hline Primary school or less & 69 & 7.0 & 89 & 7.8 & \\
\hline Middle school & 552 & 55.8 & 590 & 51.3 & \\
\hline High school & 324 & 32.8 & 385 & 33.5 & \\
\hline Post secondary school & 43 & 4.4 & 85 & 7.4 & \\
\hline Ethnicity & & & & & 0.99 \\
\hline Han & 956 & 96.9 & 1113 & 96.9 & \\
\hline Minorities & 31 & 3.1 & 36 & 3.1 & \\
\hline Marriage status & & & & & $<0.01$ \\
\hline Married & 467 & 47.7 & 454 & 41.4 & \\
\hline Single & 512 & 52.3 & 643 & 58.6 & \\
\hline Current working place & & & & & 0.39 \\
\hline No job & 24 & 2.4 & 58 & 5.0 & \\
\hline Hotel or restaurant & 164 & 16.6 & 218 & 18.9 & \\
\hline Entertainment* & 332 & 33.5 & 308 & 26.7 & \\
\hline Construction site & 234 & 23.6 & 324 & 28.1 & \\
\hline Peddler market & 103 & 10.4 & 99 & 8.6 & \\
\hline Domestic service & 53 & 5.4 & 18 & 1.5 & \\
\hline Others & 80 & 8.1 & 129 & 11.2 & \\
\hline Monthly income in US\$ & & & & & 0.04 \\
\hline$\leqslant 57$ & 147 & 14.8 & 202 & 17.4 & \\
\hline $58-80$ & 198 & 20.0 & 253 & 21.8 & \\
\hline $81-115$ & 220 & 22.2 & 241 & 20.8 & \\
\hline$>115$ & 427 & 43.0 & 465 & 40.0 & \\
\hline Mobility index & & & & & 0.06 \\
\hline $0.06-0.30$ & 248 & 25.0 & 322 & 28.7 & \\
\hline $0.31-0.49$ & 189 & 19.0 & 241 & 21.4 & \\
\hline $0.50-0.70$ & 291 & 29.3 & 274 & 24.4 & \\
\hline $0.71-1.00$ & 180 & 18.2 & 189 & 16.8 & \\
\hline $1.01-10.00$ & 84 & 8.5 & 98 & 8.7 & \\
\hline To whom resided in city & & & & & 0.84 \\
\hline Alone & 109 & 11.0 & 125 & 10.8 & \\
\hline Spouse or children & 321 & 32.4 & 386 & 33.3 & \\
\hline Otherst & 562 & 56.6 & 647 & 55.9 & \\
\hline No. of job taken & & & & & 0.84 \\
\hline 1 or no job & 298 & 30.0 & 325 & 28.0 & \\
\hline 2 & 274 & 27.6 & 360 & 31.0 & \\
\hline 3 & 233 & 23.5 & 271 & 23.3 & \\
\hline 4 & 94 & 9.5 & 90 & 7.8 & \\
\hline$>4$ & 93 & 9.4 & 115 & 9.9 & \\
\hline
\end{tabular}

living with HIV. There items include: (1) "HIV infected people should be ostracised by their spouse and family members"; (2) "HIV infected people should be forced to leave their villages"; (3) "I would not be able to maintain a normal relationship with my friends if they become infected with HIV"; and (4) "HIV infected people should not have the same rights to education and employment as others." Participants responded on a four point Likert scale, ranging from strongly agree to strongly disagree. The Cronbach alpha for this scale was 0.62. Two variables were created in data analysis: (1) a binary variable wherein individuals selected "strongly agree" or "agree" as their responses to at least one of the four items

Table 2 Migrants' responses to HIV stigmatising beliefs

\begin{tabular}{|c|c|c|c|c|c|c|c|c|c|c|}
\hline & \multicolumn{2}{|c|}{ Strongly agree } & \multicolumn{2}{|c|}{ Agree } & \multicolumn{2}{|c|}{ Disagree } & \multicolumn{2}{|c|}{ Strongly disagree } & \multicolumn{2}{|c|}{ Having stigmatising beliefs' } \\
\hline $\mathrm{Nc}$ & & $\%$ & No & $\%$ & No & $\%$ & No & $\%$ & No & $\%$ \\
\hline \multicolumn{11}{|c|}{ Item 1: HIV infected people should be ostracised by their spouse and family members } \\
\hline & 54 & 11.8 & 466 & 21.8 & 1143 & 53.2 & 284 & 13.2 & 720 & 33.5 \\
\hline \multicolumn{11}{|c|}{ Item 2: HIV infected people should be forced to leave their villages } \\
\hline 16 & 62 & 7.6 & 462 & 21.6 & 1192 & 55.5 & 328 & 15.3 & 624 & 29.1 \\
\hline \multicolumn{11}{|c|}{ Item 3: I would not be able to maintain a normal relationship with my friends if they become infected with HIV } \\
\hline 16 & 69 & 8.0 & 709 & 33.3 & 1076 & 50.7 & 169 & 8.0 & 878 & 41.4 \\
\hline \multicolumn{11}{|c|}{ Item 4: HIV infected people should not have the same rights to education and employment as others } \\
\hline 14 & 45 & 6.8 & 506 & 23.8 & 1127 & 53.0 & 349 & 16.4 & 651 & 30.6 \\
\hline
\end{tabular}


were classified as "having stigmatising beliefs," those who selected "strongly disagree" or "disagree" to all the four items as "having no stigmatising beliefs"; and, (2) a categorical variable with four levels (0: having no stigmatising response to all the four items; 1 : providing a stigmatising response to only one item; 2: stigmatising responses to two items; and 3: stigmatising responses to three or four items).

\section{Mobility}

Respondents were queried about the total years of their migratory experience and the number of cities in which they had lived during their migration. The ratio of the number of migratory cities to years of total migration was employed as an index of mobility. The mobility index of the migrants ranged from 0.06 to 10 (median 0.50) with higher values indicating higher levels of mobility. Using the ratio may control for a potential confounder "duration of migration"that is, older people may have a greater number of migratory years and number of cities. The index was then parcelled across five groupings according to its distribution (0.06-0.30, $0.31-0.49,0.50-0.70,0.71-1.00$, and $1.01-10.00)$ as shown in table 1 .

\section{HIV knowledge}

The knowledge scale consisted of 22 items, each of which required a true/false or likely/unlikely response; examples of the knowledge are, "AIDS is caused by a virus" and "Taking a shower after sex can reduce the chance of getting AIDS." The percentage of correct answers was retained as a composite score with higher scores reflecting increased knowledge about the transmission and symptoms of HIV/AIDS. The mean score of HIV knowledge in subjects was 14.1 (SD 2.89, range $0-22$ ). The Cronbach alpha for this scale was 0.78 .

\section{HIV risk behaviours}

Three items were employed to assess participants' HIV risk behaviours. The first items assessed the number of sexual partners during the previous month. Those who had had two or more sexual partners were considered to have had "multiple sexual partners." The second item asked whether they had ever had commercial sex partners (sold sex or bought sex) (yes/no). "Having had an episode of an STD" was used as a risk behaviour indicator. Subjects who had ever had a clinician confirmed episode of an STD were defined as "having a history of an STD" while those who had never had a clinician confirmed episode of an STD were defined as "having no history of an STD."

\section{Preventive practices}

HIV related preventive practices (or intentions) were assessed through two questions. The first question assessed the frequency of condom use when they had sex (always, often, sometimes, or never). The other item assessed the participants' willingness to receive an HIV test (yes/no).

\section{Analysis}

Firstly, bivariate analysis was used to estimate odds ratios (OR) and their 95\% confidence intervals (95\% CI) of the associations of stigmatising beliefs with social, demographic, and migratory characteristics and perception of HIV infection. Secondly, two models were developed to assess associations between stigmatising beliefs (regressor) and risk behaviours and preventive practices (regressand). Model 1 was an unadjusted model including only one regressor (stigmatising beliefs, binary variable) in a logistic regression model. Model 2 was a multiple logistic regression in which the associations between risky sexual behaviours and preventive practice with stigmatising beliefs (categorical variable with four levels) were assessed by controlling covariates listed in table 3 plus age and HIV/AIDS knowledge. All statistical analyses were performed using SAS (Version 9.1; SAS Institute, Cary, NC, USA).

\section{RESULTS}

\section{Stigmatising beliefs towards people with HIV}

Among the subjects, over one third (35\%) did not have a stigmatising response to any of the four items, whereas $65 \%$ had a stigmatising response to at least one item; $8 \%$ had a stigmatising response to all the four items, $12 \%$ to three items, $21 \%$ to two items, and $24 \%$ to only one item (table 2 ).

Table 3 shows the distribution of HIV related stigmatising beliefs among the study subjects. Participants having a primary school education, having a lower monthly income, or perceiving a higher risk of acquiring HIV infections had a higher degree of stigmatising beliefs towards people with HIV. Subjects having stigmatising beliefs had lower HIV/ AIDS knowledge compared to those without the stigmatising beliefs (13.8 $v 15.3$ mean scores, respectively; $t=12.1$, $\mathrm{p}<0.01)$. The presence of stigmatising beliefs was not associated with age $(t=1.1, \mathrm{p}=0.27)$.

\section{Association of HIV related stigmatising beliefs and sexual risk behaviours}

Among subjects, $7.2 \%$ (155) reported having had more than one sexual partner in the previous month, 9.9\% (213) having had commercial sex partners, and $12.5 \%$ (268) having had an episode of an STD. Of the sexually experienced, only 5.3\% (114) reported that it was possible for them to acquire an HIV infection. The results of the two models are presented in table 4. Multiple logistic regression analysis depicts that their stigmatising beliefs towards people with HIV were positively associated with having had an episode of an STD, having multiple sex partners in the previous month, or having had commercial sex partners.

\section{Association of the stigmatising beliefs with preventive practices}

Among study subjects, only 18\% (355) reported frequently or always using condoms, with $20 \%$ sometimes or occasionally using them. Fifty seven per cent (1226) were willing to take a voluntary HIV test. HIV related stigmatising beliefs were negatively associated with each preventive practice in the two models (table 4).

\section{DISCUSSION}

Findings in this study document that HIV risky sexual behaviours, including having multiple sex partners, commercial sex, and having a history of an STD as a risk indicator, were associated with increased stigmatising beliefs. One's stigmatising beliefs towards people living with HIV were also associated with a decreased probability of taking preventive practices-for example, using condoms frequently and voluntary HIV testing.

The endorsement of stigmatising beliefs may be the result of attempts to reduce the cognitive dissonance associated with engaging in the practices. According to cognitive dissonance theory, ${ }^{11}$ cognitive dissonance may be evoked when a person holds inconsistent beliefs or acts inconsistently with held beliefs. To reduce the resulting discomfort, the person is motivated to change his or her attitude so as to eliminate the inconsistency. HIV related stigma is related to identification of HIV/AIDS as a serious illness and the association of AIDS with people and groups already stigmatised before the epidemic. ${ }^{12}$ Because one's stigmatised behaviour is endangering one's dignity and health, cognitive dissonance is probably aroused. If one cognition derives from a behaviour that has already been performed, the easiest course is to change one's beliefs rather than to change one's 
Table 3 Distribution of HIV related stigmatising beliefs

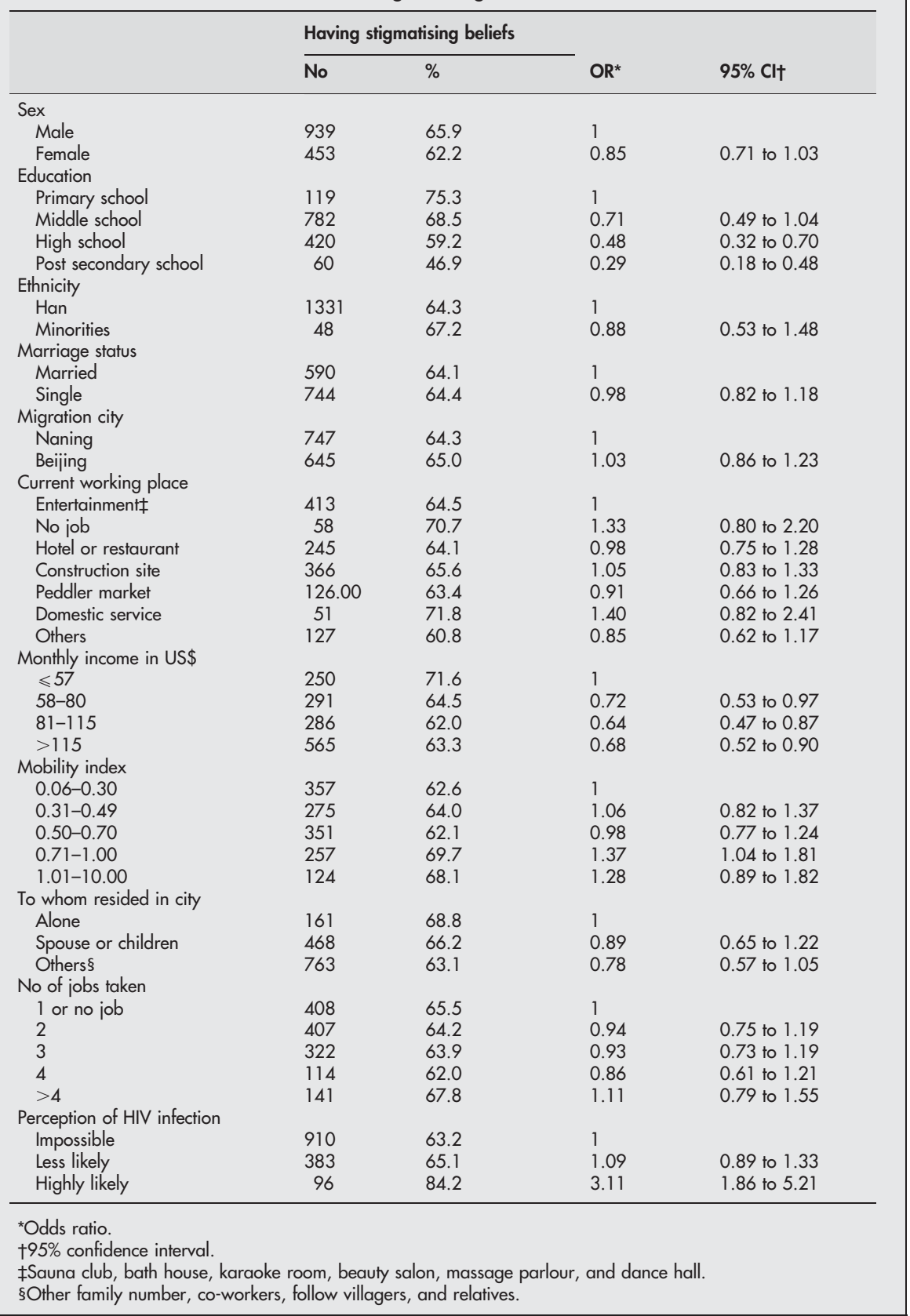

Table 4 Associations of HIV stigmatising beliefs, risk behaviours, and safer practices

\begin{tabular}{|c|c|c|c|c|c|c|c|c|c|c|}
\hline & \multicolumn{2}{|c|}{$\begin{array}{l}\text { Having had an episode } \\
\text { of STD }\end{array}$} & \multicolumn{2}{|c|}{$\begin{array}{l}\text { Having had } \\
\text { multiple sex } \\
\text { partners }\end{array}$} & \multicolumn{2}{|c|}{$\begin{array}{l}\text { Having had } \\
\text { commercial sex }\end{array}$} & \multicolumn{2}{|c|}{ Condom use } & \multicolumn{2}{|c|}{ Intention to receive HIV test } \\
\hline & ORt & $95 \% \mathrm{Cl} \ddagger$ & OR & $95 \% \mathrm{Cl}$ & OR & $95 \% \mathrm{Cl}$ & OR & $95 \% \mathrm{Cl}$ & OR & $95 \% \mathrm{Cl}$ \\
\hline \multicolumn{11}{|l|}{ Unadjusted } \\
\hline $\begin{array}{l}\text { Stigmatising beliefs* } \\
\text { Multiple logistic regression } \\
\text { Stiamatising beliefs }\end{array}$ & 2.32 & 1.70 to 3.16 & 1.75 & 1.20 to 2.54 & 1.94 & 1.39 to 2.71 & 0.60 & 0.47 to 0.76 & 0.64 & 0.54 to 0.77 \\
\hline \multicolumn{11}{|l|}{ Stigmatising beliefs } \\
\hline $2 \vee 0$ & 2.00 & 1.33 to 3.03 & 1.58 & 0.96 to 2.60 & 1.73 & 1.11 to 2.71 & 0.91 & 0.65 to 1.28 & 0.64 & 0.50 to 0.83 \\
\hline 3 or $4 \vee 0$ & 1.84 & 1.20 to 2.82 & 2.01 & 1.21 to 3.32 & 1.99 & 1.27 to 3.12 & 0.65 & 0.45 to 0.96 & 0.52 & 0.40 to 0.68 \\
\hline Goodness of fit test & \multicolumn{2}{|c|}{$\chi^{2}=9.16, p=0.33$} & \multicolumn{2}{|c|}{$\chi^{2}=9.19, p=0.33$} & \multicolumn{2}{|c|}{$\chi^{2}=7.58, p=0.48$} & \multicolumn{2}{|c|}{$\chi^{2}=8.16, p=0.42$} & \multicolumn{2}{|c|}{$\chi^{2}=5.88, p=0.66$} \\
\hline
\end{tabular}


behaviour. ${ }^{13}$ One method to justify one's stigmatised behaviours may be to blame or stigmatise people living with HIV - that is, to add a consonant cognition. By assuming that my sex partners do not have HIV, I cannot become infected; consequently, my behaviour is not so bad and will not be noticed by others. Botnick reported that one method of justifying one's unsafe sex was to blame HIV victims among homosexuals in order to reduce dissonance. ${ }^{14}$ It is also possible that people practising stigmatising behaviour may try to blend in with people without such behaviour and harmonise personal beliefs with public endorsements in an effort to maintain positive self view ${ }^{15}$ and possible selves. ${ }^{16}$ This result is similar to the one reported by Burkholder and colleagues, ${ }^{17}$ who found in a study among 481 sexually active youths that stigmatising beliefs regarding others is related to greater behavioural risk for HIV/AIDS.

Our study demonstrates that having stigmatising beliefs is negatively associated with use of condoms and voluntary HIV testing. Because condoms are often associated with casual sex, infidelity, and/or multiple partners, ${ }^{18}$ condom use itself may be stigmatised. For example, in India, a significant barrier to condom use was lack of privacy in stores. ${ }^{19}$ Effective HIV intervention requires timely testing for HIV infection and control of the sources of HIV infection in communities, including prevention of secondary infections in households. However, only half of the subjects in this study expressed willingness to undergo HIV testing, and their willingness was negatively associated with their stigmatising beliefs. HIV associated stigma contributes to the psychological burden of receiving a positive antibody test as the disclosure of the result would put them in a stigmatising condition. ${ }^{20}$ Stigmatising beliefs and fears of discrimination can influence decisions to seek HIV testing. ${ }^{10}$ In an effort to escape stigma and avoid cognitive dissonance, people may be reluctant to seek HIV testing. A survey of rural residents in China showed that HIV related discrimination and family unification were two key factors associated with the subjects' decisions to disclose HIV test results to their spouses. ${ }^{21}$ Our findings are consistent with a study conducted in South Africa that shows participants who were not tested for HIV held significantly more AIDS related stigmatising beliefs than those who had been tested..$^{22}$

This study has several limitations. Firstly, because migrants were recruited from only two cities, they might not be representative of other migrant populations in China; therefore, the findings may have limited generalisability. Secondly, the Cronbach alpha of the four items measuring HIV related stigmatising beliefs is relatively low (0.62), indicating less than optimal internal consistency. Further studies are needed to improve its reliability and validity. Thirdly, as the sample was not a random sample, some selection bias may exist. However, the relatively large sample size might minimise this bias. Finally, owing to the cross sectional nature of this study, these data should be interpreted as associations rather than implying causality.

Despite the limitations, our findings have important public health implications for HIV/AIDS intervention programmes. The finding that one's own stigmatising belief is a potential barrier to HIV related preventive practices highlights the difficulties and challenges in implementing behavioural interventions.

\section{ACKNOWLEDGEMENTS}

This study was supported by the US National Institute of Mental Health (NIMH) (grant \#R0IMH064878). We would like to thank colleagues and graduates from Beijing Normal University, Nanjing University and West Virginia University for their participation in instrument development and data collection.

\section{Key messages}

- Findings among a sample of sexually active Chinese migrants document that HIV risky sexual behaviours, including having multiple sex partners, commercial sex, and having a history of an STD as a risk indicator, were associated with increased stigmatising beliefs

- One's stigmatising beliefs towards people living with HIV were also associated with a decreased probability of taking preventive practices-for example, using condoms frequently and voluntary HIV testing

- This finding that one's own stigmatising belief is a potential barrier to HIV related preventive practices highlights the difficulties and challenges in implementing behavioural interventions.

\section{CONTRIBUTORS}

Study concept and design: HL, XL, BS, XF, RM; acquisition of data: $\mathrm{HL}, \mathrm{XF}, \mathrm{RM}$.; analysis and interpretation of results: HL XL, BS, XC, HY; drafting of the manuscript: $\mathrm{HL}, \mathrm{XL}, \mathrm{BS}, \mathrm{XC}, \mathrm{HY}$

\section{Authors' affiliations}

H Liu, X Li, B Stanton, X Chen, H Yang, Preventive Research Center, School of Medicine, Wayne State University, Detroit, MI, USA $X$ Fang, Institute of Developmental Psychology, Beijing Normal University, Beijing, China

R Mao, Institute of Mental Health and Department of Education Science and Administration, Nanjing University, Nanjing, China

Conflict of interest: None of the authors have any conflict of interest associated with this study.

Ethics approval: This research study was approved by the institutional review boards at West Virginia University and Wayne State University in the United States and the collaborating institutes in China (for example, Beijing Normal University and Nanjing University), and was conducted in full accordance with ethical principles, including the provisions of the World Medical Association Declaration of Helsinki, and free and informed consent was obtained from all human subjects.

\section{REFERENCES}

1 UNAIDS. 2004 report on the global HIV/AIDS epidemic, 4th global report. Geneva: UNAIDS, 2004

2 Anderson AF, Qingsi Z, Hua X, et al. China's floating population and the potential for HIV transmission: a social-behavioral perspective. AIDS Care 2003;15:177-85.

3 Li X, Stanton B, Fang X, et al. HIV/AIDS risk behavior and perception among young rural-to-urban migrants in China. AIDS Edu Prev 2004;16:538-56.

4 Liu H, Detels R, Xie J, et al. A study of sexual behavior among rural residents of China. J Acquir Immune Defic Syndr 1998;19:80-8.

5 UNAIDS. A joint assessment of HIV/AIDS prevention, treatment and care in China. Beiijing: UNAIDS China Office, 2003

6 Lau JTF, Tsui HY. Surveillance of discriminatory attitudes toward people living with HIV/AIDS among the general public in Hong Kong from 1994 to 2000. Disabil Rehab 2003;25:1354-1360.

7 Goffman E. Stigma: notes on the management of spoiled identity. Englewood Cliffs, NJ: Prentice Hall, 1963.

8 Herek GM, Capitanio JP. AIDS stigma and contact with persons with AIDS: effects of direct and vicarious contact. J Appl Soc Psychol 1997:27:1-36.

9 Parker R, Aggleton P. HIV and AIDS-related stigma and discrimination: a conceptual framework and implications for action. Soc Sci Med 2003;57:13-24.

10 Chesney MA, Smith AW. Critical delays in HIV testing and care: the potential role of stigma. Am Behar Scientist 1999;42:1162-74.

11 Festinger L. A theory of cognitive dissonance. Stanford, CA: Stanford University Press, 1957.

12 Herek GM, Glunt EK. An epidemic of stigma. Public reactions to AIDS. Am Psychol 1988;43:886-91.

13 Goethals GR. Dissonance and self-justification. Psychological Inquiry 1992;3:327-9.

14 Botnick MR. Part 2: Fear of contagion, fear of intimacy. J Homosex 2000;39:77-101.

15 Taylor S, Brown J. Illusion and well-being: a social psychological perspective on mental health. Psychol Bul 1988;103:198-210. 
16 Brown L. Ethnic stigma as a contextual experience: a possible selves perspective. Personality and Social Psychological Bulletin 1998;24:163-72.

17 Burkholder GJ, Harlow LL, Washkwich J-L. Social stigma, HIV/AIDS knowledge, and sexual risk. J Appl Biobehav Res 1999;4:27-44.

18 Holschneider SO, Alexander CS. Social and psychological influences on HIV preventive behaviors of youth in Haiti. $J$ Adolesc Health 2003;33:31-40.

19 Roth J, Krishnan SP, Bunch E. Barriers to condom use: results from a study in Mumbai (Bombay), India. AIDS Edu Prev 2001;13:65-77.
20 Stall R, Hoff C, Coates TJ, et al. Decisions to get HIV tested and to accept antiretroviral therapies among gay/bisexual men: implications for secondary prevention efforts. J Acquir Immune Defic Syndr 1996;1 1:151-60.

21 Liu H, Ma Z, Yu W. [Attitude to voluntary HIV testing and result disclosure among rural residents in China]. Chung-Hua Yu Fang i Hsueh Tsa Chih [Chinese Journal of Preventive Medicine] 2001;35:30-2.

22 Kalichman SC, Simbayi LC. HIV testing attitudes, AIDS stigma, and voluntary HIV counselling and testing in a black township in Cape Town, South Africa. Sex Transm Infect 2003;79:442-7. 